$\overline{\text { Original }}$

\title{
Flavor Production from Edible Oils and Their Constituents by Penicillium corylophilum
}

(Received December 19, 2001)

\author{
Hiroshi Fujikawa*1, ${ }^{\dagger}$, Akihiro Ibe*1, Tomoaki Wauke*1, Satoshi Morozumi ${ }^{* 1}$ \\ and Haruhiko MoRi*2 \\ (*1 Tokyo Metropolitan Research Laboratory of Public Health: 3-24-1, Hyakunin-cho, Shinjuku-ku, \\ Tokyo 169-0073, Japan; ${ }^{* 2}$ Takaki Bakery Co.: 3-7-1, Nakano-Higashi, Aki-ku, \\ Hiroshima $739-0323$, Japan; ${ }^{\dagger}$ Corresponding author)
}

\begin{abstract}
Production of volatile substances from edible oils and their constituents by Penicillium corylophilum was studied to clarify the mechanism of flavor production from a non-stick oil by the organism in a rice cake system. First, edible oils from plant and animal origins were tested for flavor production. Among the oils tested, coconut oil was the only one from which the flavor was produced. Second, triacylglycerols consisting of fatty acids with various lengths of carbon chain $\left(\mathrm{C}_{6}\right.$ to $\left.\mathrm{C}_{13}\right)$ were studied for flavor production. Among the triacylglycerols tested, flavors were produced from those consisting of fatty acids with carbon chains of $\mathrm{C}_{6}$ to $\mathrm{C}_{11}$. The flavors consisted of methylketones and secondary alcohols, whose carbon chains were one carbon shorter than the precursor fatty acid molecules of the triacylglycerols. Flavors similar to that from the non-stick oil were produced from tricaprylin $\left(\mathrm{C}_{8}\right)$, trinonanoin $\left(\mathrm{C}_{9}\right)$, and tridecanoin $\left(\mathrm{C}_{10}\right)$ among the triacylglycerols tested. Formation of mould spores was more strongly suppressed by triacylglycerols with shorter chain fatty acids. Third, fatty acids with various lengths of carbon chain $\left(C_{7}\right.$ to $\left.C_{15}\right)$ were studied for flavor production. Among the fatty acids tested, flavors were produced from decanoic $\left(\mathrm{C}_{10}\right)$ and undecanoic $\left(\mathrm{C}_{11}\right)$ acids only. The flavors also consisted of methylketones and secondary alcohols one carbon shorter than the precursor fatty acids. Fatty acids with short carbon chains $\left(\mathrm{C}_{7}\right.$ to $\left.\mathrm{C}_{9}\right)$ completely inhibited the mould growth. Our study showed that the range of carbon chain length of fatty acids capable of the flavor production $\left(\mathrm{C}_{10}\right.$ to $\left.\mathrm{C}_{11}\right)$ was narrower than that of triacylglycerols $\left(\mathrm{C}_{6}\right.$ to $\left.\mathrm{C}_{11}\right)$. It was also found that the non-stick oil and coconut oil contain tricaprylin and tridecanoin as triacylglycerols and decanoic acid as fatty acid.
\end{abstract}

Key words: flavor; volatile substance; non-stick oil; coconut oil; edible oil; triacylglycerol; fatty acid; mould

\section{Introduction}

Recently we have reported on an apple-like flavor production in rice cake products ${ }^{11}$. A non-stick oil had been sprayed on the rice cake products during a cutting process. It was found that Penicillium corylophilum, a contaminant of the oil, produced the flavor in the sprayed rice cake. The flavor consisted of four volatile substances, including methylketones (2-heptanone and 2-nonanone) and secondary alcohols (2-heptanol and 2nonanol). The flavor was also produced from coconut oil, which was one of the ingredients of the non-stick oil. Further, we found that most of the moulds tested had a potential to produce the flavor from the non-stick oil, whereas none of the bacteria or yeast tested did. It is now important to know the characteristics and/or mechanism of the flavor production from the non-stick oil by moulds from the viewpoint of food hygiene to prevent the occurrence of unfavorable odor production in foods.
The fundamental structural component of oil is triacylglycerol, which consists of three fatty acids and one glycerol ${ }^{2,3)}$. It is known that fatty acids are released from triacylglycerols by lipases of microorganisms, especially moulds, and that volatile substances such as methylketones are produced from fatty acids by

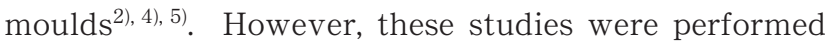
mainly for flavors of specific foods and foodstuffs, such as cheese, bread, and mushroom ${ }^{4-6}$. Systematic studies on flavor production by moulds from oils and their constituents (triacylglycerols and fatty acids) with carbon chains of various lengths have hardly been done. Especially, no such studies on triacylglycerols have been reported so far. In this paper, therefore, we conducted such studies using P. corylophilum.

\section{Materials and Methods}

\section{Microorganism}

P. corylophilum (P-3) was isolated from the non-stick oil in our laboratory ${ }^{1)}$. 


\section{Rice cake}

Rice cake products without any flavor or microbial contamination were purchased at a retail shop in Tokyo.

\section{Edible oils}

Edible oils of plant and animal origins, including olive oil, canola oil, safflower oil, sesame oil, lard, milk fat (butter), and beef tallow were purchased at retail shops in Tokyo. Coconut oil and the non-stick oil were donated by Miyoshi Oil Co., Tokyo and the rice cake producer $^{1)}$, respectively.

\section{Chemicals}

Methylketones (2-pentanone, 2-hexanone, 2-heptanone, 2-nonanone, and 2-decanone) and secondary alcohols (2-pentanol, 2-hexanol, 2-heptanol, 2-nonanol, and 2-decanol) were obtained from Wako Pure Chemical Industries, Tokyo. Fatty acids (heptanoic acid, octanoic (caprylic) acid, nonanoic acid, decanoic (capric) acid, undecanoic acid, dodecanoic (lauric) acid, tridecanoic acid, tetradecanoic (myristic) acid, and pentadecanoic acid) and triacylglycerols (tricaproin, trioenanthin, tricaprylin, trinonanoin, tridecanoin, triundecanoin, trilaurin, and tritridecanoin) were purchased from Funakoshi Co., Tokyo. Triacylglycerols with fatty acids of shorter carbon chain length (less than six carbon atoms) were unavailable from the producer (Funakoshi).

\section{Flavor production in the rice cake system}

P. corylophilum spore suspension $\left(5 \times 10^{3}\right.$ cells $\left./ \mathrm{mL}\right)$ was prepared by the method of Fujikawa et al. ${ }^{1}$. Mixtures of $5 \mathrm{~g}$ of rice cake and $0.5 \mathrm{~mL}$ of water were sterilized in 50-mL glass tubes with tight glass caps at $100^{\circ} \mathrm{C}$ for $15 \mathrm{~min}$. After having been cooled at room temperature, a $0.5-\mathrm{mL}$ portion of the spore suspension and a chemical test sample $(0.5 \mathrm{~g}$ of oil, $150 \mathrm{mg}$ of triacylglycerol, or $150 \mathrm{mg}$ of fatty acid) were inoculated into the glass tubes. The oils had been sterilized at $121^{\circ} \mathrm{C}$ for $15 \mathrm{~min}$. The mixtures in the glass tubes were incubated at $25^{\circ} \mathrm{C}$ for 2 weeks in duplicate. Controls without the spore inoculation were also incubated.

\section{Chemical analysis of flavor}

Ten-milliliter portions of ethyl acetate were mixed into the incubated rice cake samples ${ }^{1)}$. After filtration, portions of the sample layers were injected into a gasliquid chromatograph/mass spectrometer (GCMS-QP 5000, Shimadzu Co., Kyoto, Japan) for chemical analysis of flavors produced ${ }^{1)}$.

\section{Sensory test of flavor}

Flavors that were produced in the rice cake samples were evaluated by four panelists of our laboratory ${ }^{1)}$.

\section{Mould growth}

Mould growth of samples incubated in the rice cake system was observed with the naked eye. Also, small portions of rice cake samples were microscopically ob- served and incubated on potato dextrose agar plates (Eiken Chemicals, Tokyo) at $25^{\circ} \mathrm{C}$ for one week ${ }^{7}$.

\section{Results and Discussion}

\section{Flavor production from edible oils}

Production of flavor from several kinds of edible oil by $P$. corylophilum was studied in the rice cake system, which had been shown to be suitable for a flavor production experiment using moulds ${ }^{1)}$. The sensory test showed that no flavors were produced from olive oil, canola oil, safflower oil, sesame oil, lard, milk fat, and beef tallow by the mould and that the flavor from the non-stick oil was produced from coconut oil only. Our previous study showed that the ingredients of the flavor from coconut oil were the same as those from the non-stick oil ${ }^{1)}$. Mould growth of the samples supplemented with the edible oils was good, similar to that of the control without oil.

The carbon chain lengths of fatty acids of edible oils of animal and plant origins are generally long, mostly ranging from 16-22 carbon atoms, such as palmitic acid $\left(\mathrm{C}_{16}\right)$, linoleic acid $\left(\mathrm{C}_{18}\right)$ and stearic acid $\left(\mathrm{C}_{18}\right)^{3), 8)}$. Compared with these edible oils, coconut oil contains triacylglycerols consisting of medium-chain fatty acids mainly with less than 14 carbon atoms, which are much characteristic of this oil ${ }^{8)}$. It was, therefore, suggested that the medium-chain fatty acids of coconut oil could be substrates affording the flavor of concern.

\section{Flavor production from triacylglycerols}

Flavor production from triacylglycerols consisting of saturated fatty acids with short to medium carbon chains $\left(\mathrm{C}_{6}\right.$ to $\left.\mathrm{C}_{13}\right)$ by the mould was studied in the rice cake system.

The sensory study revealed that flavors similar to that from the non-stick oil were produced from tricaprylin $\left(\mathrm{C}_{8}\right)$, trinonanoin $\left(\mathrm{C}_{9}\right)$, and tridecanoin $\left(\mathrm{C}_{10}\right)$ (Table 1). The flavors consisted of methylketones and secondary alcohols, whose carbon chains were one carbon shorter than those of the component fatty acids of the triacylglycerols (Table 1). Trace amounts of 2nonanone $\left(\mathrm{C}_{9}\right), 2$-heptanol $\left(\mathrm{C}_{7}\right)$, 2-heptanone $\left(\mathrm{C}_{7}\right)$, and 2 hexanone $\left(\mathrm{C}_{6}\right)$ were also produced from trinonanoin $\left(\mathrm{C}_{9}\right)$.

The sensory test also showed that flavors were produced from tricaproin $\left(\mathrm{C}_{6}\right)$ and trioenanthin $\left(\mathrm{C}_{7}\right)$ by the mould, but they were very different from the flavor of concern from the non-stick oil (Table 1). Also, a large amount of 2-decanone was produced from triundecanoin, but the flavor of concern was observed only very faintly in this sample (Table 1). This was because 2-decanone is not a flavorful substance. Also, 2decanol, which was produced in a very small quantity from triundecanoin, is an odorless substance. In the samples without the mould inoculation, neither flavors nor volatile substances were produced from the triacylglycerols tested.

Hawke ${ }^{6}$ proposed a modified beta-oxidation pathway of fatty acids for the production of methylketones and secondary alcohols. It is thought that through this 
Table 1. Production of Volatile Substances from Triacylglycerols by P. corylophilum

\begin{tabular}{|c|c|c|c|c|c|c|c|c|}
\hline \multirow{2}{*}{ Triacylglycerols } & \multicolumn{8}{|c|}{ Volatile substances ( $\mu \mathrm{g} / \mathrm{tube})$} \\
\hline & 2-Pentanone & 2-Pentanol & 2-Hexanone & 2-Hexanol & 2-Heptanone & 2-Heptanol & 2-Octanone & 2-Octanol \\
\hline Tricaproin $\left(\mathrm{C}_{6}\right)$ & 14,057 & $\underline{1,544}$ & - & - & - & - & - & - \\
\hline Trioenanthin $\left(\mathrm{C}_{7}\right)$ & - & $\overline{-}$ & 14,254 & 2,374 & - & - & - & - \\
\hline Tricaprylin $\left(\mathrm{C}_{8}\right)$ & - & - & - & $\overline{-}$ & 22,849 & $\underline{1,423}$ & - & - \\
\hline Trinonanoin $\left(\mathrm{C}_{9}\right)$ & - & - & $<50$ & - & 388 & $\overline{<50}$ & $\underline{13,683}$ & $\underline{1,093}$ \\
\hline Tridecanoin $\left(\mathrm{C}_{10}\right)$ & - & - & - & - & - & - & - & - \\
\hline Triundecanoin $\left(\mathrm{C}_{11}\right)$ & - & - & - & - & - & - & - & - \\
\hline Tridodecanoin $\left(\mathrm{C}_{12}\right)$ & - & - & - & - & - & - & - & - \\
\hline Tritridecanoin $\left(\mathrm{C}_{13}\right)$ & - & - & - & - & - & - & - & - \\
\hline Non-stick oil & - & - & - & - & 7,313 & 1,969 & - & - \\
\hline None & - & - & - & - & - & - & - & - \\
\hline \multirow{2}{*}{ Triacylglycerols } & \multicolumn{6}{|c|}{ Volatile substances ( $\mu \mathrm{g} /$ tube) } & & \\
\hline & 2-Nonanone & 2-Nonanol & 2-Decanone & 2-Decanol & Flavor $^{1}$ & Growth ${ }^{2}$ & & \\
\hline Tricaproin $\left(\mathrm{C}_{6}\right)$ & - & - & - & - & $\mathrm{D}^{3}$ & + & & \\
\hline Trioenanthin $\left(\mathrm{C}_{7}\right)$ & - & - & - & - & $\mathrm{D}$ & + & & \\
\hline Tricaprylin $\left(\mathrm{C}_{8}\right)$ & - & - & - & - & H & + & & \\
\hline Trinonanoin $\left(\mathrm{C}_{9}\right)$ & 221 & - & - & - & $H$ & H & & \\
\hline Tridecanoin $\left(\mathrm{C}_{10}\right)$ & $\underline{14,371}$ & $\underline{1,493}$ & - & - & H & H & & \\
\hline Triundecanoin $\left(\mathrm{C}_{11}\right)$ & - & $\overline{-}$ & $\underline{14,131}$ & $<50$ & + & m & & \\
\hline Tridodecanoin $\left(\mathrm{C}_{12}\right)$ & - & - & - & $\overline{-}$ & - & m & & \\
\hline Tritridecanoin $\left(\mathrm{C}_{13}\right)$ & - & - & - & - & - & m & & \\
\hline Non-stick oil & 5,060 & 910 & - & - & m & H & & \\
\hline None & - & - & - & - & - & m & & \\
\hline
\end{tabular}

Figures show the averages of four samples in two experiments. - means negative.

Underlined figures are volatile substances that might be formed by Hawke's pathway as described in the text.

${ }^{1}$ Magnitudes of flavor production were determined by the sensory test.

2 Magnitudes of the mould growth were determined from the spore formation.

${ }^{3}$ Production of a flavor different from the control (the non-stick oil)

pathway, methylketones and secondary alcohols one carbon shorter are produced from the precursors, or fatty acids, by microbial enzymes. This pathway may yield the methylketones and secondary alcohols of interest here. The main volatile products from the triacylglycerols tested in this study could be formed in this way. These products are underlined in Table 1 .

Our study clarified that the suitability of triacylglycerols as substrates for Hawke's pathway was limited by the carbon chain length of its fatty acids. The "upper" limit for length was triundecanoin $\left(\mathrm{C}_{11}\right)$. From triacylglycerols containing longer fatty acids, such as tridodecanoin $\left(\mathrm{C}_{12}\right)$, neither flavor nor any volatile substance was produced (Table 1). The "lower" limit was not determined in this study. That is, tricaproin $\left(\mathrm{C}_{6}\right)$, which contained the shortest chain fatty acid in this study, was a substrate for the pathway (Table 1); triacylglycerols containing shorter fatty acids $\left(<\mathrm{C}_{6}\right)$ were not available.

Spore formation of the mould was more strongly suppressed by triacylglycerols with shorter chain fatty acids (Table 1). As the carbon chain length of the triacylglycerol tested was increased, the color tone of the colonies grown in the rice cake system became heavier. The magnitude of spore formation of the mould was measured in terms of the color tone (dark, pale green) of the mould colonies, because spores of the mould are colored specifically and the hyphae are colorless $^{9}$. The color tone, or spore formation of the control with the non-stick oil was located between those of trinonanoin $\left(\mathrm{C}_{9}\right)$ and tridecanoin $\left(\mathrm{C}_{10}\right)$ among the samples tested. This is consistent with the fact that the volatile substances from the non-stick oil were produced from tricaprylin $\left(\mathrm{C}_{8}\right)$, trinonanoin $\left(\mathrm{C}_{9}\right)$, and tridecanoin $\left(\mathrm{C}_{10}\right)$ among the triacylglycerols (Table 1 ). Hyphal growth for all the samples in the presence of the triacylglycerols was good.

\section{Flavor production from fatty acids}

Saturated fatty acids with 7-15 carbon atoms were studied for flavor production by the mould in the rice cake system.

The sensory test revealed that flavors similar to that from the non-stick oil were produced only from decanoic acid $\left(\mathrm{C}_{10}\right)$ and undecanoic acid $\left(\mathrm{C}_{11}\right)$ among the fatty acids tested (Table 2). The chemical analysis showed that the flavor from decanoic acid consisted of mainly 2-nonanone and 2-nonanol, and that that from undecanoic acid consisted of mainly 2-decanone and 2decanol (Table 2). The main volatile products from the fatty acids tested in this study were considered to have been formed via Hawke's pathway, as in the case of the 
Table 2. Production of Volatile Substances from Fatty Acids by P. corylophilum

\begin{tabular}{|c|c|c|c|c|c|c|c|c|c|c|}
\hline \multirow{2}{*}{ Fatty acids } & \multicolumn{10}{|c|}{ Volatile substances ( $\mu \mathrm{g} /$ tube) } \\
\hline & 2-Heptanone & 2-Heptanol & 2-Octanone & 2-Octanol & 2-Nonanone & 2-Nonanol & 2-Decanone & 2-Decanol & Flavor $^{1}$ & Growth $^{2}$ \\
\hline Heptanoic acid & - & - & - & - & - & - & - & - & - & - \\
\hline Octanoic acid & - & - & - & - & - & - & - & - & - & - \\
\hline Nonanoic acid & - & - & - & - & - & - & - & - & - & - \\
\hline Decanoic acid & 115 & - & 60 & - & 4,777 & 1,335 & 101 & - & H & H \\
\hline Undecanoic acid & 103 & - & 219 & - & 336 & $\overline{-}$ & $\underline{99,560}$ & 2,620 & + & H \\
\hline Dodecanoic acid & - & - & - & - & - & - & - & $\overline{-}$ & - & H \\
\hline Tridecanoic acid & - & - & - & - & - & - & - & - & - & m \\
\hline Tetradecanoic acid & - & - & - & - & - & - & - & - & - & m \\
\hline Pentadecanoic acid & - & - & - & - & - & - & - & - & - & H \\
\hline Non-stick oil & 5,494 & 859 & - & - & 4,100 & 251 & - & - & m & H \\
\hline None & - & - & - & - & - & - & - & - & - & m \\
\hline
\end{tabular}

Figures show the averages of four samples in two experiments. - means negative.

Underlined figures are volatile substances that might be formed by Hawke's pathway as described in the text.

${ }^{1}$ Magnitudes of flavor production were determined by the sensory test.

${ }^{2}$ Magnitudes of the mould growth were determined from the hyphal elongation and spore formation.

triacylglycerols. These products are underlined in Table 1. Trace amounts of other volatile substances such as 2-octanone and 2-heptanone were also produced from these fatty acids (Table 2). For the samples without mould inoculation, neither flavors nor volatile substances were produced from the fatty acids tested.

These results suggested that the flavor from the nonstick oil would be derived mainly from decanoic acid as a fatty acid; the volatile substances of the flavor of concern, other than 2-heptanol, were produced from this acid. Large amounts of 2-decanone and 2-decanol were produced from undecanoic acid, but production of the flavor of concern was low by the sensory test (Table 2 ). This was possibly because 2-nonanone and 2heptanone, which are constituents of the flavor of concern, were produced in low amounts (Table 2) and 2decanone has a very faint flavor, as described above.

The magnitude of spore formation of the mould was observed in terms of the color tone of colonies in the presence of the long chain fatty acids studied $\left(\mathrm{C}_{10}\right.$ to $\mathrm{C}_{15}$ ), as with the triacylglycerols (Table 2). For the long chain fatty acids, the longer the carbon chain of the fatty acid, the heavier the color tone of the sample. The color tone of the colony with the non-stick oil was located between those of the samples with decanoic acid $\left(\mathrm{C}_{10}\right)$ and with undecanoic acid $\left(\mathrm{C}_{11}\right)$. This is consistent with the fact that the volatile substances from the non-stick oil were produced from decanoic and undecanoic acids (Table 2). Other investigators have also reported that methylketones were produced from fatty acids by moulds during sporulation ${ }^{6)}, 10$ ).

Growth of the mould was strongly suppressed by the fatty acids with short carbon chains $\left(\mathrm{C}_{7}\right.$ to $\left.\mathrm{C}_{9}\right)$ (Table 2$)$. Neither hyphal growth nor spore formation of the mould was observed. Also, no viable mould cells were observed in those samples. Naturally, this non-growth led to non-production of any flavor from those samples. It is known that propionic acid $\left(\mathrm{C}_{3}\right)$, a very short chain fatty acid, inhibits microbial growth and is used as a food preservative ${ }^{11), 12)}$. It was newly found that short chain fatty acids of heptanoic to nonanoic acids $\left(\mathrm{C}_{7}\right.$ to
$\mathrm{C}_{9}$ ) also inhibited mould growth in this study.

The transformation of fatty acid by Hawke's pathway was found to be limited by the carbon chain length of the acid in this study. The "lower" limit was governed by the suppressive action of short-chain fatty acids, as described above; decanoic acid $\left(\mathrm{C}_{10}\right)$ was the shortest fatty acid from which a flavor was produced (Table 2). There was also an "upper" limit for the length of carbon chain. From dodecanoic acid $\left(\mathrm{C}_{12}\right)$ and longer chain fatty acids, neither flavors nor volatile substances were produced by $P$. corylophilum (Table 2). It is known that moulds do not produce methylketones from long chain fatty acids $^{10)}$.

This study showed that the range of acceptable chain lengths for triacylglycerols was wider than that for fatty acids; the range for triacylglycerols was $\mathrm{C}_{6}-\mathrm{C}_{11}$, while that of the fatty acids was $\mathrm{C}_{10}-\mathrm{C}_{11}$. That is, the difference was in fatty acids with less than 10 carbon atoms. These short-chain fatty acids completely suppressed the mould growth, while the triacylglycerols containing these short-chain fatty acids did not (Tables 1 and 2). It is thought that fatty acids were released from the triacylglycerols by lipases of the mould and subsequently processed into volatile substances by enzymes of mould cells that grew well in the rice cake samples. In the fatty acid experiment, the inoculated mould cells were exposed directly to the fatty acids, some of which were harmful to the mould, from the beginning of incubation. This might account for the difference. Further physiological and biochemical studies on mould cells should be helpful to confirm this.

The proposed production pathway indicates that the four volatile substances of the flavor from the non-stick oil and coconut oil should be produced from octanoic $\left(\mathrm{C}_{8}\right)$ and decanoic $\left(\mathrm{C}_{10}\right)$ acids as fatty acids and tricaprylin $\left(\mathrm{C}_{8}\right)$ and tridecanoin $\left(\mathrm{C}_{10}\right)$ as triacylglycerols. However, the volatile substances were not produced from octanoic acid due to its suppressive action on mould growth. These facts suggested that the non-stick oil contains tricaprylin and tridecanoin as triacylglycerols (or decanoic acid as a fatty acid). 
Our previous study demonstrated that most of moulds had a potential to produce flavors from the non-stick oil ${ }^{1)}$. In a preliminary study, some fungi other than $P$. corylophilum were studied for the flavor production from triacylglycerols and fatty acids in the rice cake system. As a result, Aspergillus niger, which produced the flavor from the non-stick oil in a large amount ${ }^{1)}$, produced 2-decanone and 2-decanol from undecanoic acid and 2-nonanone and 2-nonanol from decanoic acid, like $P$. corylophilum. Also, growth of $A$. niger was inhibited by short-chain fatty acids (data not shown). Thus, the results obtained with $P$. corylophilum may be generally applicable to many moulds.

\section{References}

1) Fujikawa, H., Ibe, A., Wauke, T., Morozumi, S., Mori, H., Flavor production from a non-stick oil by moulds. J. Food Hyg. Soc. Japan, 42, 7-12 (2001).

2) Madigan, M. T., Martinko, J. M., Parker, J., "Brock Biology of Microorganisms", 9th Ed., Prentice Hall, 2000.

3) Metzler, D. E., "Biochemistry", New York, Academic Press, 1977, p. 108-115.

4) Kinderlerer, J.L., Volatile metabolites of filamentous fungi and their role in food flavour. J. Appl. Bacteriol. (Suppl.), 133S-144S (1989).
5) Kellard, B., Busfield, D. M., Kinderlerer, J. L., Volatile offflavour compounds in desiccated coconut. J. Sci. Food Agric., 36, 415-420 (1985).

6) Anonymous, "Yusikagaku Binran (Handbook for Oil Chemistry)", 3rd Ed., Japan Oil Chemist Society, 1990.

7) Anonymous, "Shokuhin Eisei Kensa Shishin (Standard Methods of Analysis in Food Safety Regulation)", Tokyo, Japan Food Hygiene Association, 1993.

8) Häusler, A., Münch, T., Microbial production of natural flavors. ASM News, Washington, American Society for Microbiology, 551-559 (1997).

9) Hawke, J.C., Reviews of the progress of dairy science. Section D. Dairy chemistry. The formation and metabolism of methylketones and related compounds. J. Dairy Res., 33, 225-243 (1966).

10) Pitt, J. I., "The genus Penicillium and its teleomorphic states Eupencillium and Talaromyces", London, Academic Press, 1979, p. 294-297.

11) De Boer, E., Nielsen, P. V., Introduction to Food-borne Fungi", 4th Ed., Baarn (The Netherlands), Centraalbureau voor Schimmelcultures, 1995.

12) Matsuda, T., Yano, T., Maruyama, A., Kumagai, H., Antimicrobial activities of organic acids determined by minimum inhibitory concentrations at different $\mathrm{pH}$ ranged from 4.0 to 7.0. Nippon Shokuhin Kogyo Gakkaishi, 41, 687-702 (1994). 